\title{
MICROSTRUCTURE AND TEXTURE OF IN SITU HEAVILY DRAWN $\mathrm{Cu}-\mathrm{Nb}$ COMPOSITES
}

E. N. POPOVA ${ }^{\mathrm{a}, *}$, V. V. POPOV ${ }^{\mathrm{a}}$, L. A. RODIONOVA ${ }^{\mathrm{a}}$, S. V. SUDAREVA ${ }^{\text {a }}$, E. P. ROMANOV ${ }^{\mathrm{a}}$, A. E. VOROBYOVA ${ }^{\mathrm{b}}$, N. E. HLEBOVA ${ }^{b}$, V. I. PANTSYRNYI ${ }^{b}$ and A. K. SHIKOV ${ }^{b}$

${ }^{a}$ Institute of Physics of Metals, Urals Div. of RAS, Ekaterinburg, Russia;

${ }^{\mathrm{b}}$ Bochvar All-Russian Institute of Inorganic Materials, Moscow, Russia

(Received 4 May 2000; In final form 29 May 2000)

Heavily cold drawn in situ $\mathrm{Cu}-\mathrm{Nb}$ composites have been investigated by transmission electron microscopy (TEM) and X-ray analysis. Dislocation density in the copper matrix has been shown to change only slightly in the investigated drawing ratio range because of the development of stage IV of deformation. In $\mathrm{Nb}$ filaments dislocation density in the investigated range at first increases with deformation and then drops at the highest drawing ratio. At intermediate deformation niobium grains consist of fine blocks separated by low-angle dislocation boundaries. At drawing, fibre texture develops in both phases, with $\langle 111\rangle$ and $\langle 100\rangle$ axis for the copper matrix and $\langle 110\rangle$ axis for niobium filaments. Besides, niobium filaments acquire ribbon-like form, and their grains possess certain orientation, namely, in interlacing grains crystallographic $\{311\},\{100\}$ and $\{111\}$ planes are parallel to each other and to the filament plane, i.e., the rolling texture with $\{311\}\langle 110\rangle,\{100\}\langle 110\rangle$ and $\{111\}\langle 110\rangle$ components is forming within every filament.

Keywords: In situ composites; Drawing; X-ray diffraction; Transmission electron microscopy (TEM); Fibre texture; Rolling texture

\section{INTRODUCTION}

Deformation-processed heavily drawn $\mathrm{Cu}-\mathrm{Nb}$ composites possess an extremely high strength, appreciably greater than that predicted by the

*Address for correspondence: Institute of Metal Physics, Urals Div. of RAS, GSP-170, S. Kovalevskaya Str., 18, Ekaterinburg 620219, Russian Federation. e-mail: popova@ imp.uran.ru 
rule of mixtures for the constituent phases (Bevk, Harbison and Bell, 1978; Karasek and Bevk, 1979; Spitzig, Pelton and Laabs, 1987). These composites are usually formed by the so-called in situ method using a two-phase alloy as an initial material. During the deformation processing $\mathrm{Nb}$ dendrites transform into ribbon-like filaments with axial texture of $\langle 110\rangle$ type. With an increase of deformation degree filament spacing and thickness decrease, and the growth of strength correlates with interphase spacing (Funkenbusch and Courtney, 1981).

Two basic explanations were proposed for the enormously high strength of heavily deformed in-situ composites: the so-called substructural strengthening (Funkenbusch and Cortney, 1985) and the barrier mechanism (Spitzig, Pelton and Laabs, 1987). The model of substructural strengthening attributes the excess strengthening to generation of additional geometrically necessary dislocations in comparison with similarly deformed single-phase materials. According to the barrier model high strength is a result of difficulty of propagating plastic flow through $\mathrm{FCC} / \mathrm{BCC}$ interfaces. Both models predict an influence of texture on strength through the Taylor factor.

According to experimental results both models predict linear dependence of strengthening on $\lambda^{-1 / 2}$ (where $\lambda$ is an average filament spacing), i.e., the dependence of Hall-Petch type, and using some fitting parameters they can describe deformation strengthening of these materials. However, as the discussion of these two mechanisms has shown (Funkenbusch and Courtney, 1990a, b; Spitzig et al., 1990a, b), neither of them give a complete picture of deformation behavior of such composites.

Despite a large number of publications investigating structure evolution and textures in heavily deformed $\mathrm{Cu}-\mathrm{Nb}$ composites, there remain some questions to be clarified. This is particularly true in regard to $\mathrm{Nb}$ filaments, as the main attention in the above-mentioned researches was paid to structure and texture of the copper matrix. For example, the values of dislocation densities in $\mathrm{Nb}$ filaments, presented in different publications (Bevk et al., 1978; Pelton, 1987; Spitzig et al., 1987; Spitzig, 1991; Popova et al., 1997), vary by several orders of magnitude. Thus, at present there is no complete understanding of deformation-induced structure evolution in these materials, and further investigations are necessary. 
The main goal of this work was to study fine structure and texture of heavily drawn in situ $\mathrm{Cu}-\mathrm{Nb}$ composites, especially their $\mathrm{Nb}$ filaments, using X-ray analysis along with TEM investigations to obtain more reliable values of dislocation densities.

\section{EXPERIMENTAL PROCEDURE}

Samples for investigation were in situ prepared from ingots of $\mathrm{Cu}-20 \% \mathrm{Nb}$. Initial rods were extruded to $30 \mathrm{~mm}$ in diameter. Then they were cold drawn to $10 \mathrm{~mm}$ in diameter, annealed at $700^{\circ} \mathrm{C}$ for $1 \mathrm{~h}$ and again cold drawn to final diameters of $1.0,0.67$ and $0.3 \mathrm{~mm}$ with wire drawing reductions (true strain) equal to $6.8,7.6$ and 9.21, respectively. The latter were calculated as $\eta=\ln \left(A_{0} / A\right)$, where $A_{0}$ and $A$ are the initial (after extrusion) and final cross sectional areas. These samples were prepared in the Bochvar All-Russian Institute of Inorganic Materials (Moscow).

Microstructure of the samples was TEM examined in JEM-200CX electron microscope. Thin foils for these investigations were prepared as follows. Pieces of wire about $15 \mathrm{~mm}$ long were mechanically thinned to about $0.1 \mathrm{~mm}$ thick, and then the obtained plates were chemically polished in 3:2:1 mixture of $\mathrm{HNO}_{3}, \mathrm{H}_{2} \mathrm{SO}_{4}$ and $\mathrm{HF}$ concentrated acids.

Texture was analyzed on base of the obtained TEM data. Texture axis was determined by juxtaposing a large number of electron micrographs with electron diffraction patterns (EDPs) from the same areas with a correction for image turn. Crystallographic directions in the phases present coinciding with that of niobium fiber elongation and drawing direction were revealed.

Indexes of crystallographic planes, corresponding to the planes of ribbon-like filaments, were determined according to EDPs in cases when the latter were perpendicular to the electron beam. Perpendicularity of a filament plane to the direction of electron beam was achieved with the help of a goniometer.

$\mathrm{X}$-ray investigations were carried out using X-ray diffractometer DRON-3 M with $\mathrm{CuK}_{\alpha}$ radiation. The step size was $0.01^{\circ}$ with the exposure for $20 \mathrm{sec}$. Samples for these investigations were prepared as follows. Pieces of wire about $10 \mathrm{~mm}$ length were stuck close together 
on a plastic plate, mechanically ground to obtain a flat surface, and then chemically polished to remove a strain hardened layer of about $0.1 \mathrm{~mm}$ thick.

Microstructure parameters were determined using the approximation method described by Umansky et al. (1982) and Rusakov (1977). Diffraction profiles $(111)_{\mathrm{Cu}},(311)_{\mathrm{Cu}},(110)_{\mathrm{Nb}}$ and $(211)_{\mathrm{Nb}}$ were taken for specimens (experimental profiles) and standards (instrumental profiles), the latter being pure vacuum annealed copper and niobium. The preliminary analysis of the diffraction profiles have shown that they are best of all approximated with a $\left(1+\gamma X^{2}\right)^{-2}$ function. In that case the relationship between the integral widths of the true profile $(\beta)$, the experimental profile $(B)$ and the instrumental broadening profile (b) is expressed as follows (Rusakov, 1977):

$$
\beta=0.5 B(1-b / B+\sqrt{1-b / B})
$$

Two diffraction profiles were taken for every phase to separate contributions to true diffraction profile broadening resulting from the dispersity of coherent scattering areas (CSA), $\beta_{M}$, and microstrains, $\beta_{N}$. Diffraction profile due to dispersity of CSA was supposed to be approximated by $\left(1+\gamma X^{2}\right)^{-1}$ function, while that due to microstrains was approximated by $\left(1+\gamma X^{2}\right)^{-2}$ function. According to Rusakov (1977) such an approximation is the best one for cubic crystals. In that case the integral width of the true profile is related to the constituents as follows:

$$
\beta=\frac{\left(\beta_{M}+2 \beta_{N}\right)^{2}}{\beta_{M}+4 \beta_{N}}
$$

CSA size $(D)$ and microstrains $(e)$ were calculated with the following equations:

$$
\begin{aligned}
& D=\frac{0.94 \lambda}{\beta_{M} \cos \theta} \\
& e=\frac{1}{4 \beta_{N} \operatorname{tg} \theta},
\end{aligned}
$$

where $\lambda$ is the wavelength and $\theta$ is the Bragg angle. 
Dislocation density in composite components was calculated according to Umansky (1982) as:

$$
\rho=\frac{8 e^{2}}{a^{2}}
$$

where $a$ is the dislocation Burger's vector. Determination of dislocation density according to (5) is based on the assumption that the dislocations are mainly located inside the CSAs and not in their boundaries.

\section{RESULTS AND DISCUSSION}

The results of X-ray analysis of $\mathrm{Cu}$ matrix fine structure after different degrees of cold drawing are presented in Table I. As can be seen from the table, the broadening of diffraction profiles of $\mathrm{Cu}$ matrix results mainly from microstrains suggesting relatively big sizes of CSA. CSA size for specimens drawn to $\eta=6.8$ and 7.6 is more than $150,{ }^{1}$ and only after the highest deformation degree $(\eta=9.21)$ it decreases to $100 \mathrm{~nm}$. This result is in good agreement with the data of Spitzig et al. (1987) who also showed that grain and subgrain sizes in $\mathrm{Cu}$ matrix are, as a rule, greater than $150 \mathrm{~nm}$, and that it doesn't possess block structure.

Due to relatively big size of CSA the dislocation densities calculated from X-ray data are sufficiently reliable, as only a small part of dislocations is concentrated in grain and subgrain boundaries. Table I shows only slight changes of dislocation density with the increase of

TABLE I Contributions to the integral width of $\mathrm{Cu}$ matrix true diffraction profiles from CSA dispersity $\left(\beta_{M}\right)$ and microstrains $\left(\beta_{N}\right)$, CSA sizes $(D)$, microstrains $(e)$ and dislocation densities $(\rho)$ of specimens with different drawing reduction

\begin{tabular}{|c|c|c|c|c|c|c|c|c|}
\hline $\begin{array}{l}\text { Final } \\
\text { diam., } \\
\text { mm }\end{array}$ & $\eta$ & $\begin{array}{c}\beta_{M}^{(111)}, \\
\text { rad }\end{array}$ & $\begin{array}{c}\beta_{N}^{(111)}, \\
\text { rad }\end{array}$ & $\begin{array}{c}\beta_{M}^{(311)}, \\
\text { rad }\end{array}$ & $\begin{array}{c}\beta_{N}^{(311)}, \\
\text { rad }\end{array}$ & $\begin{array}{l}D, \\
n m\end{array}$ & $e$ & $\begin{array}{c}\rho, \\
10^{10} / \mathrm{cm}^{2}\end{array}$ \\
\hline 1.00 & 6.80 & 0.0009 & 0.0032 & 0.0011 & 0.0080 & $>150$ & 0.0022 & 4.9 \\
\hline 0.67 & 7.60 & 0.0007 & 0.0035 & 0.0009 & 0.0088 & $>150$ & 0.0024 & 5.9 \\
\hline 0.30 & 9.21 & 0.0016 & 0.0035 & 0.0021 & 0.0089 & 100 & 0.0025 & 6.1 \\
\hline
\end{tabular}

\footnotetext{
${ }^{1}$ When CSA are greater than $150 \mathrm{~nm}$, the broadening is too small to be determined with sufficient accuracy.
} 
deformation in the investigated range: at first it slightly increases with $\eta$ increasing from 6.8 to 7.6 , and then remains practically constant. Dislocation densities of $\mathrm{Cu}$ matrix evaluated from TEM investigations are nearly the same.

These results are in agreement with those of Spitzig et al. (1987, 1990); Pelton et al. (1987) and Spitzig (1991). In these publications it is stated that at high degrees of deformation dislocation density of $\mathrm{Cu}$ matrix is stabilized and doesn't exceed $10^{10}-10^{11} \mathrm{~cm}^{-2}$. Note that their values were obtained from TEM investigations and are in good agreement with our X-ray data. These authors attribute such a behavior of $\mathrm{Cu}$ matrix to the fact that in heavily deformed composites the stored energy is so enhanced that dislocation annihilation mechanism is engaged, and dislocation free subgrains are formed. In that case dynamic recovery and even recrystallization of $\mathrm{Cu}$ matrix are observed, and it acquires the structure characteristic of stage IV of deformation described by Rigney et al. (1986) and Sevillano and Aernoudt (1987).

The analysis of a number of electron diffraction patterns (EDPs) has shown that the $\mathrm{Cu}$ matrix of cold drawn composites acquires the two component fibre texture with $\langle 111\rangle$ and $\langle 100\rangle$ axes. This texture is also characteristic of pure heavily deformed copper wires. However, many papers (Spitzig, 1991; Raabe and Hangen, 1995a, b) report of only one orientation, namely $\langle 111\rangle$. On the other hand, some authors (e.g., Spitzig et al., 1987) observed both of them. It seems likely that this discrepancy results from the change of the relationship between texture components with deformation. The latter is evidenced by Spitzig et al., 1987.

According to Trybus and Spitzig (1989), dynamic recovery and recrystallization in cold-rolled copper start at $\eta=1.2$ and 3.0, correspondingly. In composites these processes can be expected to start at about the same degrees of deformation. It is therefore evident that, starting from these values, the dislocation density will be more and more slightly affected by the increase of deformation degree. According to Spitzig (1991), in case of pure copper strengthening is observed up to $\eta=8.2$, and dislocation density may be also expected to increase in this interval. From these considerations the dislocation behavior of $\mathrm{Cu}$ matrix observed in the present work can be explained as follows. In the 6.8-7.6 range of deformation dislocation density 
slightly increases. This means that at lower deformations processes of recovery and recrystallization already occur, but there is no equilibrium between generation and annihilation of dislocations. At higher deformation degrees this equilibrium is reached, and further deformation doesn't affect dislocation densities in copper matrix.

Let us consider the evolution of niobium filaments. After deformation with $\eta=6.8-7.6$ they consist of grains elongated along the drawing direction separated by flat high-angle boundaries (Fig. 1). EDP analysis has shown that drawing direction and elongation of grains coincide with one of $\langle 110\rangle$ crystallographic directions, i.e., the classical BCC fibre texture develops in niobium filaments of the investigated composites. Besides, it was found that in the majority of the studied EDPs the same crystallographic planes of $\mathrm{Nb}$ coincide with the plane of the foil, namely $\{311\},\{100\}$ and $\{111\}$. Juxtaposition of EDPs with dark-field images in different reflections have shown that in interlacing $\mathrm{Nb}$ grains the indicated planes are parallel to each other and to that of the ribbon-like filament. This is the case illustrated by Figure 1. The presented dark-field images demonstrate grains, for which $\{100\}$ and $\{111\}$ planes coincide with the filament plane, and in the corresponding EDP the three planes mentioned above can be seen.

Thus, it is reasonably safe to suggest that a limited fibre texture similar to the rolling texture, with $\{100\}\langle 110\rangle,\{111\}\langle 110\rangle$ and $\{311\}\langle 110\rangle$ components is forming in $\mathrm{Nb}$ filaments of in situ composites. According to Umansky (1982), these components are characteristic of niobium rolling texture.

The development of the limited fibre texture within every filament may be supposed to result from the fact that their deformation does not possess axial symmetry due to peculiarities of BCC-crystals deformation. As shown by Bevk et al. (1978), Nb filaments acquire ribbon-like form during the development of $\langle 110\rangle$ axial texture because only two of four easy sliding directions of $\langle 111\rangle$ type are oriented favorably relative to the deformation axis. Consequently, further deformation results in plane strain instead of axially symmetric flow, and transverse sections of filaments acquire rectangular or elliptic form. However, this scheme of deformation was suggested for single crystals, but our TEM investigations have shown $\mathrm{Nb}$ filaments in heavily drawn composites to consist of several grains separated with high-angle boundaries. Conceivably the latter is due to dislocation 
rearrangement in filaments that have already acquired the ribbon-like form. Trybus and Spitzig (1989) observed the similar effect in heavily cold-rolled $\mathrm{Cu}-\mathrm{Nb}$ composites. They have found that, while at lower deformation degrees $(\eta=6)$ the dislocations are distributed randomly, at $\eta=6.9$ they rearranged into low-angle boundaries parallel to
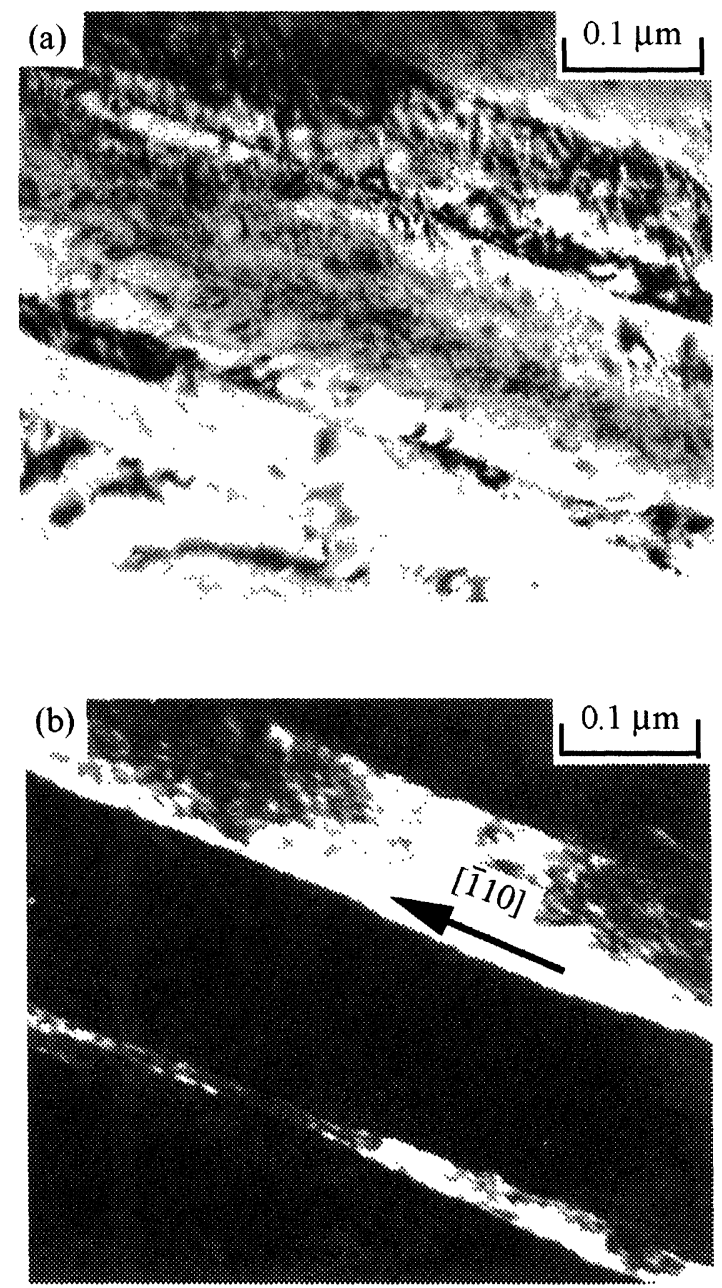

FIGURE 1 TEM micrographs of in situ composite $0.67 \mathrm{~mm}$ in diameter $(\eta=7.60)$ : $\mathrm{a}$ - bright-field image; $\mathrm{b}$ - dark-field image in $(\overline{101})_{\mathrm{Nb}}$ reflection, $\mathrm{c}$ - dark-field image in $(200)_{\mathrm{Nb}}$ reflection, $\mathrm{d}$ - electron diffraction pattern (EDP), zone axis [111]\|[100]|[311]. 

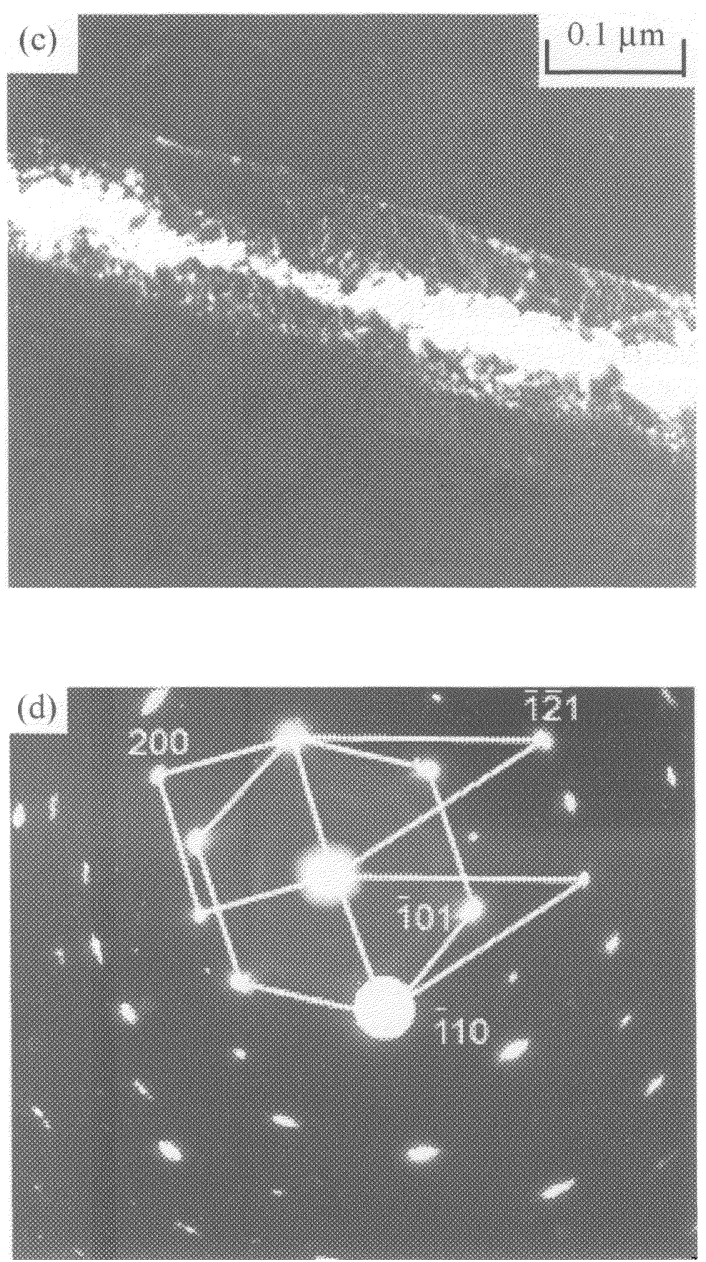

FIGURE 1 (Continued).

$\langle 110\rangle_{\mathrm{Nb}}$ directions. Pelton et al. (1987) examined $\mathrm{Nb}$ filaments chemically extracted from heavily-drawn $\mathrm{Cu}-20 \% \mathrm{Nb}$ composite and found that at deformations with $\eta>7$ they possess nearly parallel boundaries along $\langle 110\rangle$ directions, separating areas with relative disorientation of about $2-35^{\circ}$.

It may be also assumed that the formation of the limited fibre texture in niobium filaments is a result of deformation under 
conditions of their intricate interaction with the surrounding FCCcopper matrix.

The results of X-ray investigations of niobium filament structure after different degrees of drawing are presented in Table II. As can be seen from the table, in this case true broadening mainly results from CSA dispersity, and an accurate determination of dislocation density from X-ray data becomes difficult. That is why the calculated values are not presented in the table. The CSA size monotonously decreases from 9.3 to $5.7 \mathrm{~nm}$ with deformation increasing from 6.80 to 9.21 .

Figure 2 demonstrates microphotographs of niobium filament structure after different degrees of deformation. The pronounced block structure is clearly seen in these photos. Niobium grains consist of fine blocks separated with low-angle dislocation boundaries. The sizes of the latter are about $5-20 \mathrm{~nm}$, which is in agreement with the results of X-ray investigations. Dislocation density in $\mathrm{Nb}$ filaments of these two specimens is high; it ranges from $10^{11}$ to $10^{12} \mathrm{~cm}^{-2}$. These values are actually close to the upper limit of electron-microscopic determination of dislocation densities (Hirsh et al., 1965), thus, it's quite difficult to evaluate them with sufficient accuracy. Besides, dislocations are located mainly in block boundaries, which causes complications in X-ray evaluation of their density, as it was mentioned above. Nevertheless, both X-ray and electron-microscopic data definitely demonstrate the increase of dislocation density with deformation increasing from 6.8 to 7.6. This is shown by the fact that with deformation growth in this interval the average size of blocks decreases, whereas microstrains increase. The former means the growth of the amount of dislocations in block boundaries, and the latter testifies to the increase of their density inside the blocks.

Figure 3 shows the structure of the composite deformed with drawing ratio $\eta=9.21$. It can be seen that niobium filaments became

TABLE II Contributions to integral widths of $\mathrm{Nb}$ filament true diffraction profiles from CSA dispersity $\left(\beta_{M}\right)$ and microstrains $\left(\beta_{N}\right)$. CSA sizes $(D)$ and microstrains $(e)$ of specimens with different drawing reduction

\begin{tabular}{lccccccc}
\hline $\begin{array}{l}\text { Final } \\
\text { diam., } m m\end{array}$ & $\eta$ & $\begin{array}{c}\beta_{M}^{(110)}, \\
\text { rad }\end{array}$ & $\begin{array}{c}\beta_{N}^{(110)}, \\
\text { rad }\end{array}$ & $\begin{array}{c}\beta_{M}^{(211)}, \\
\text { rad }\end{array}$ & $\begin{array}{c}\beta_{N}^{(211)}, \\
\text { rad }\end{array}$ & $\begin{array}{c}D, \\
n m\end{array}$ & $e$ \\
\hline 1.00 & 6.80 & 0.0165 & 0.0025 & 0.0190 & 0.0050 & 9.3 & 0.0016 \\
0.67 & 7.60 & 0.0197 & 0.0042 & 0.0226 & 0.0083 & 7.8 & 0.0027 \\
0.30 & 9.21 & 0.0270 & 0.0019 & 0.0310 & 0.0037 & 5.7 & 0.0012 \\
\hline
\end{tabular}



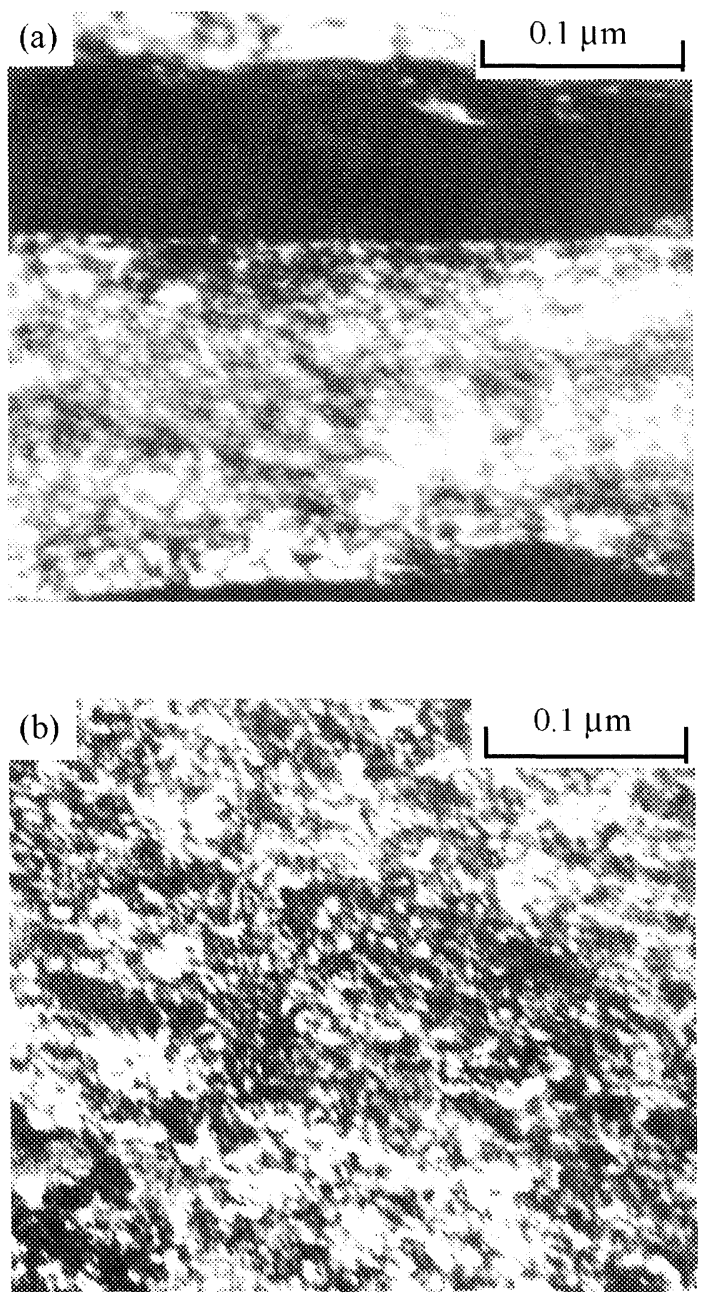

FIGURE 2 Dark-field images of niobium filaments in $(100)_{\mathrm{Nb}}$ reflections: a composite diameter $1 \mathrm{~mm}(\eta=6.80) ; \mathrm{b}$ - composite diameter $0.67 \mathrm{~mm}(\eta=7.60)$.

considerably thinner, and their grain structure disappeared. At this highest degree of deformation filaments are curved and twisted, being acted on by the surrounding FCC-copper matrix, which undergoes axially symmetric flow contrary to BCC- niobium filaments (Bevk et al., 1978). At this drawing reduction degree the block structure of the latter appears only slightly, and the decrease of CSA 

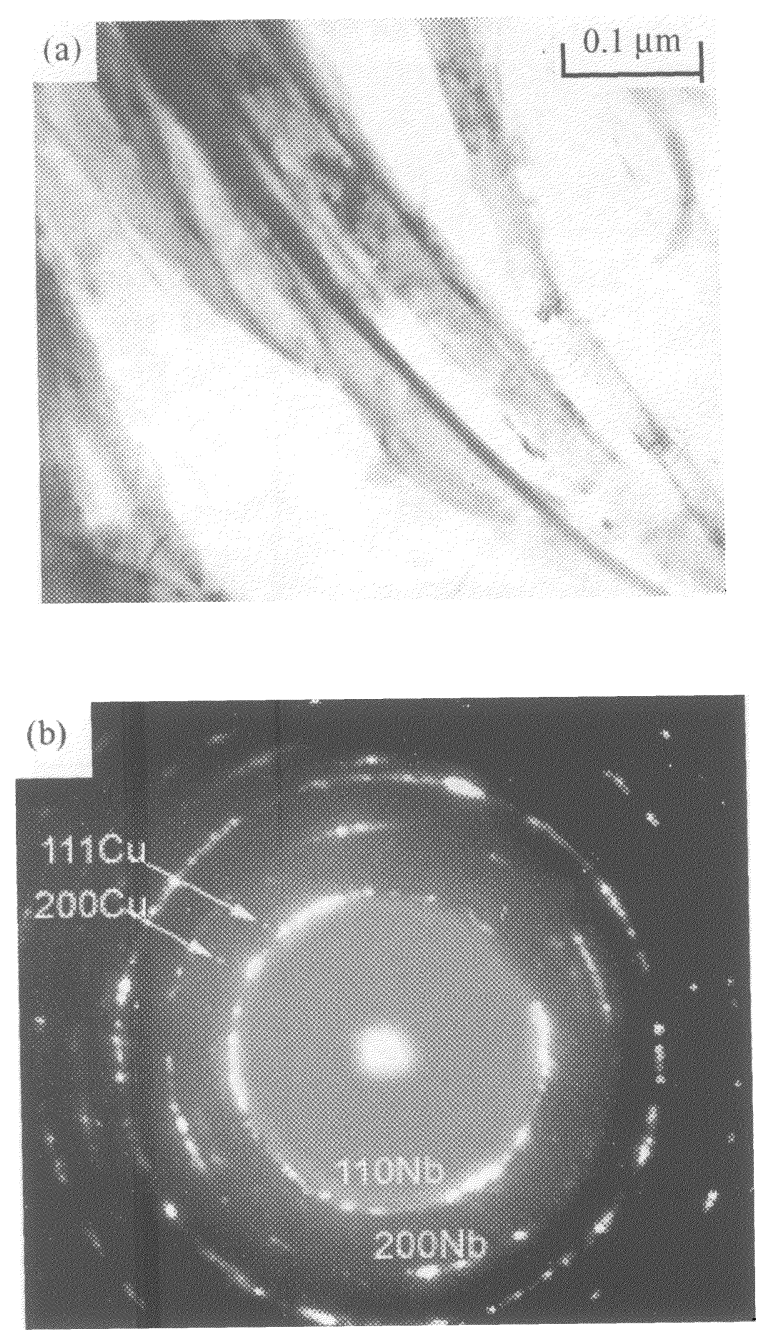

FIGURE 3 TEM micrographs of in situ composite $0.30 \mathrm{~mm}$ in diameter $(\eta=9.21)$ : $\mathrm{a}$ - bright-field image; $\mathrm{b}$ - Electron diffraction pattern (EDP).

compared to that of lesser-deformed specimens more likely results from the refining of filaments, rather than the reduction of blocks. In this case the dislocation density of niobium filaments can be evaluated according to X-ray data with sufficient accuracy, and it equals to $1.7 \cdot 10^{10} \mathrm{~cm}^{-2}$. Electron-microscopic determination of this parameter gives approximately the same value. 
As mentioned above, there is little reliable data on dislocation densities in niobium filaments of in situ composites. Thybus and Spitzig (1989) state that it is difficult to determine this parameter because of very small niobium filament thickness. However, based on the results obtained for filaments extracted from composite with $\eta=$ 6.9 drawing reduction, they conclude that dislocation density is not high, being about $10^{10} \mathrm{~cm}^{-2}$ as in the case of copper matrix. In their opinion, this is proved by the presence of low-angle boundaries in the extracted $\mathrm{Nb}$ filaments.

Bevk et al. (1978) and Spitzig et al. (1987) also report low dislocation densities in $\mathrm{Nb}$ filaments of heavily deformed $(\eta>7)$ composites. Bevk et al. (1978) attribute the drastic drop of dislocation density at high deformation to the fact that in thin filaments their boundaries act as dislocation sinks.

Our data for intermediate drawing reductions $(\eta=6.8-7.6)$ are not in good agreement with these results, dislocation densities in $\mathrm{Nb}$ filaments being about an order of magnitude higher and, contrary to that of the copper matrix, considerably growing with deformation. At higher deformations $(\eta=9.21)$ this parameter was found to decrease to about $10^{10} \mathrm{~cm}^{-2}$.

Thus, in niobium filaments unlike the copper matrix dislocation density varies not monotonously, increasing at intermediate deformations and then dropping in very thin heavily deformed filaments. Such intricate dislocation behavior of in situ composites indicates that relatively simple models of deformation strengthening, i.e., the socalled one parameter models, are not physically reasonable.

\section{CONCLUSIONS}

Fine structure investigations of in situ $\mathrm{Cu}-20 \% \mathrm{Nb}$ heavily drawn composite wire have shown dislocation density of copper matrix to vary only slightly in the draw ratio range of $6.80-9.21$, providing support for previously stated belief that in copper matrix the IV stage of deformation is observed.

Investigation of dislocation structure in niobium filaments has shown dislocation density to change non-monotonously with deformation. In the range of intermediate deformations $(\eta=6.8-7.6) \mathrm{Nb}$ filaments consist of grains elongated in drawing direction and 
separated by plane boundaries with common $\langle 110\rangle$ crystallographic direction. These grains consist of blocks 5-20 nm size separated with low-angle dislocation boundaries. The main portion of dislocations is grouped in block boundaries. The dislocation density in this deformation range is growing with deformation, its average value being about $10^{11}-10^{12} \mathrm{~cm}^{-2}$. At higher drawing reduction $(\eta=9.21)$ filaments decrease in size and their dislocation density drastically drops to a value of about $10^{10} \mathrm{~cm}^{-2}$.

Texture studies have shown both phases to acquire sharp fibre texture in the process of drawing. For copper matrix the texture axis are $\langle 111\rangle$ and $\langle 100\rangle$, whereas for $\mathrm{Nb}$ it is $\langle 110\rangle$. Besides, grains in ribbon-like niobium filaments have been shown to acquire certain orientation relatively to a filament plane, namely, one of three $\mathrm{Nb}$ crystallographic planes $(\{311\},\{100\}$ or $\{111\})$ in neighboring grains coincide with that of the filament. This suggests formation of the limited texture in $\mathrm{Nb}$ filaments with $\{311\}\langle 110\rangle,\{100\}\langle 110\rangle$ and $\{111\}\langle 110\rangle$ components.

\section{Acknowledgments}

The authors would like to gratefully acknowledge Professor B. K. Sokolov, Institute of Metal Physics Ural Div. of RAS, for stimulating discussions and valuable remarks.

\section{References}

Bevk, J., Harbison, J. P. and Bell, J. L. (1978) Anomalous increase in strength of in situ formed $\mathrm{Cu}-\mathrm{Nb}$ multifilamentary composites. Journal of Applied Physics, 49, $6031-6038$.

Funkenbusch, P. D. and Courtney, T. H. (1981) Microstructural strengthening in cold worked in situ $\mathrm{Cu}-14.8$ vol.\% Fe composites. Scripta Metall., 15, 1349-1354.

Funkenbusch, P. D. and Courtney, T. H. (1985) On the strength of heavily cold worked in situ composites. Acta Met., 33, 913-922.

Funkenbusch, P. D. and Courtney, T. H. (1990a) Reply to Comments on "On the role of interphase barrier and substructural strengthening in deformation processed composite materials". Scripta Metall. et Mater., 24, 1175-1180.

Funkenbusch, P. D. and Courtney, T. H. (1990b) Further comments on strengthening in deformation processed composite materials (DPCM). Scripta Metall. et Mater., 24, 1183-1184.

Hangen, U. and Raabe, D. (1995) Modelling of the yield strength of a heavily wire drawn $\mathrm{Cu}-20 \% \mathrm{Nb}$ composite by use of a modified linear rule of mixtures. Acta Metall. Mater., 43, 4075-4082. 
Hirsh, P. B., Howie, A., Nicholson, R. B. et al., Electron Microscopy of Thin Crystals. London, Butterworths, 1965.

Karasek, K. R. and Bevk, J. (1979) High temperature strength of in situ formed $\mathrm{Cu}-\mathrm{Nb}$ multifilamentary composites. Scripta Metall., 13, 259-262.

Pelton, A. R., Laabs, F. C., Spitzig, W. A. and Chen, C. C. (1987) Microstructural analysis of in-situ copper-niobium composite wires. Ultramicroscopy, 22(1-4), $251-265$.

Popova, E. N., Rodionova, L. A., Popov, V. V., Sudareva, S. V., Romanov, E. P., Vorobyova, A. E. et al. (1997) Microstructure and strengthening mechanisms of $\mathrm{Cu}-\mathrm{Nb}$ composites. Physics of Metals and Metallography, 84, 538-539.

Raabe, D. and Hangen, U. (1995) Introduction of a modified linear rule of mixtures for the modelling of the yield strength of heavily wire drawn in situ composites. Composites Sci. and Tech., 55, 57-61.

Rigney, D. A., Naylor, M. G. S. and Divakar, R. (1986) Low energy dislocation structures caused by sliding and by particle impact. Mater. Sci. Eng., 81, 409-425.

Rusakov, A. A. (1977) X-ray Studies of Metals. Moscow, Atomizdat (in Russian).

Sevillano, J. G. and Aernoudt, E. (1987) Low energy dislocation structures in highly deformed materials. Mater. Sci. Eng., 86, 35-51.

Spitzig, W. A., Pelton, A. R. and Laabs, F. C. (1987) Characterization of the strength and microstructure of heavily cold worked $\mathrm{Cu}-\mathrm{Nb}$ composites. Acta Met., 35, $2427-2442$.

Spitzig, W. A., Verhoeven, J. D., Trybus, C. L. and Chumbley, L. S. (1990) Comments on "On the role of interphase barrier and substructural strengthening in deformation processed composite materials". Scripta Metall. et Mater., 24, $1171-1174$.

Spitzig, W. A., Verhoeven, J. D., Trybus, C. L. and Chumbley, L. S. (1990) Reprise to Comments on "On the role of interphase barrier and substructural strengthening in deformation processed composite materials". Scripta Metall. et Mater., 24, $1181-1182$.

Spitzig, W. A. (1991) Strengthening in heavily deformation processed $\mathrm{Cu}-20 \% \mathrm{Nb}$. Acta Metal Mater., 39, 1085-1090.

Trybus, C. L., Chumbley, L. S., Spitzig, W. A. and Verhoeven, J. D. (1989) Problems in evaluating the dislocation densities in heavily deformed $\mathrm{Cu}-\mathrm{Nb}$ composites. Ultramicroscopy, 30, 315-320.

Trybus, C. L. and Spitzig, W. A. (1989) Characterization of the strength and the structural evolution of heavily cold rolled $\mathrm{Cu}-20 \% \mathrm{Nb}$ composite. Acta Met., 37, $1971-1981$.

Umansky, Ya. S., Skakov, Yu. A., Ivanov, A. I. and Rastorguev, L. I. (1982) Crystallography, X-ray Analysis and Electron Microscopy. Moscow, Metallurgiya (in Russian). 